6. Salvato RS, Gregianini TS, Campos AAS, et al. Epidemiological investigation reveals local transmission of SARS-CoV-2 lineage P.1 in Southern Brazil. Res Sq 2021. doi: 10.21203/rs.3.rs-280297/v1.

7. Silva MS, Demoliner M, Hansen AW, et al. Early detection of SARS-CoV-2 P.1 variant in Southern Brazil and reinfection of the same patient by P.2. Res Sq 2021. doi: 10.21203/rs.3.rs-435535/v2.
8. Martins AF, Zavascki AP, Wink PL, et al. Detection of SARS-CoV-2 lineage P.1 in patients from a region with exponentially increasing hospitalisation rate, February 2021, Rio Grande do Sul, Southern Brazil. Euro Surveill 2021;26:2100276.

\title{
How human behavior will lead to the next pandemic
}

\author{
Nikolaos Mazonakis MD ${ }^{1}$, loulia Markaki MD² and Nikolaos Spernovasilis MD, MPH ${ }^{1}$ (]) \\ ${ }^{1}$ School of Medicine, University of Crete, Heraklion, Greece and "'Sotiria" General Hospital for Thoracic Diseases, Athens, Greece
}

To the Editor-Since the outbreak of coronavirus disease 2019 (COVID-19), scientists have been pondering over the causative factors that are essential for infectious diseases to emerge. Many interpret pandemics solely as the result of the expanding human population, but this may be a half truth. The overall choices we make on a political, socioeconomic, and personal level determine the likelihood of the next outbreak to occur (Fig. 1). The major epidemic and pandemic outbreaks of the last few decades were caused by zoonoses. Zoonotic species, especially viruses and protozoa, are twice as likely to emerge in comparison to nonzoonotic species. ${ }^{1}$ Continuous interactions between humans and wild animals increase the risk of emerging diseases. A study in the AsianAustralasian region revealed that those wild mammals that predominantly harbor emerging pathogens are 15 times more likely to use a human modified environment compared to other wild mammals in the same region. ${ }^{2} \mathrm{~A}$ typical case of this human-animal interface is bushmeat hunting for human consumption, which not only leads to species extinction but also promotes transmission of previously unknown infectious agents to humans. ${ }^{3}$ Urban wildlife markets are present in many parts of the world, creating pathways for zoonotic diseases to thrive. For example, the probable origin of COVID-19 was a wildlife market in the city of Wuhan, China. ${ }^{4}$ Illegal wildlife trade, a profitable business with tremendous financial interests, increases human exposure to wildlife vectors, resulting in the emergence of infectious diseases. ${ }^{5}$ All of these factors reflect the human greed and ceaseless need for intervention in ecosystems with a single purpose, human benefit.

Apart from wildlife trade, deforestation also brings humans closer to the wild and opens the gate for the spread of emerging diseases. Urbanization, land use for industrial farming, monocul-

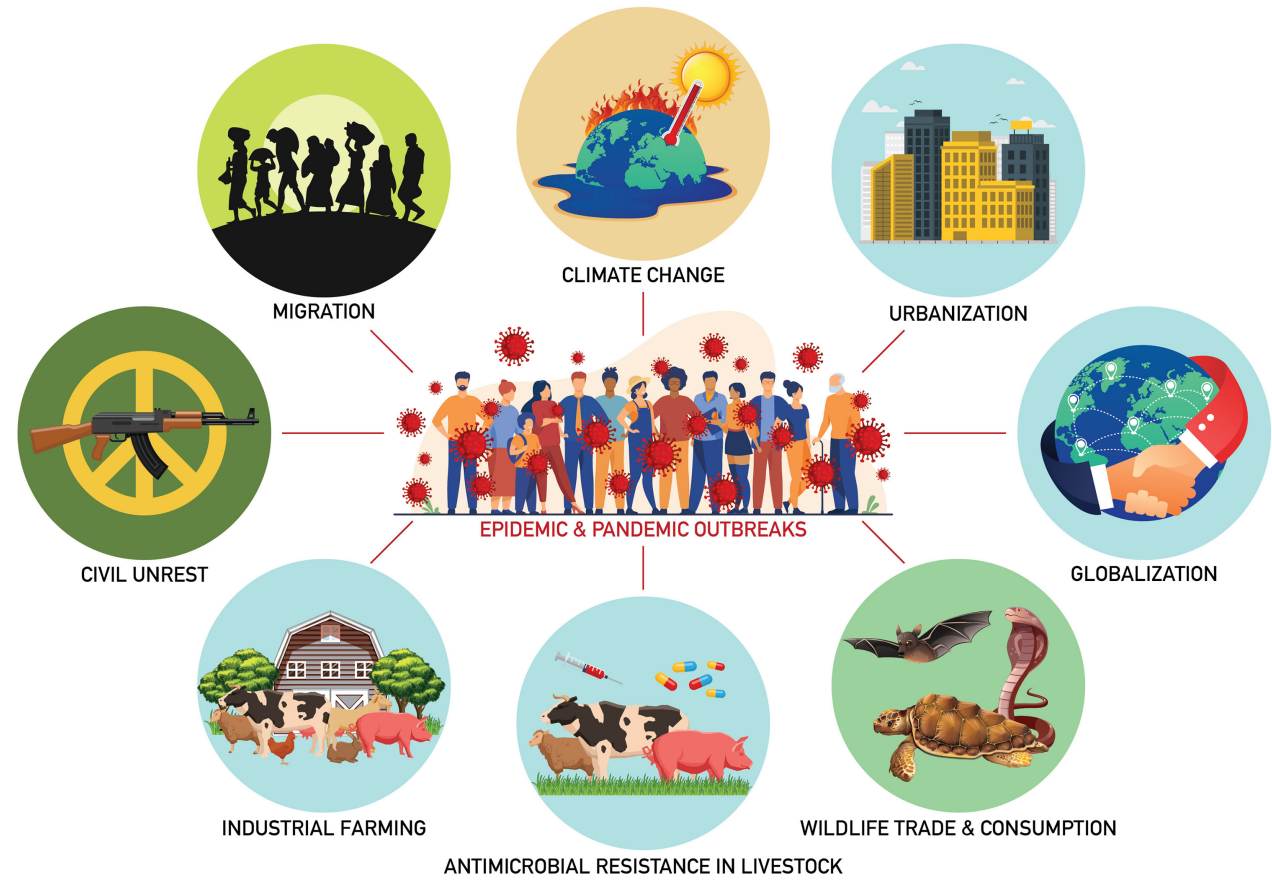

Fig. 1. Major drivers of the emergence of epidemics and pandemics.
Author for correspondence: Nikolaos Spernovasilis, E-mail: nikspe@hotmail.com Cite this article: Mazonakis N, Markaki I, and Spernovasilis N. (2022). How human behavior will lead to the next pandemic. Infection Control \& Hospital Epidemiology, 43: 1999-2000, https://doi.org/10.1017/ice.2021.455 ture tree plantations, especially for the production of palm oil, and wildfires, which are increasing exponentially due to global warming, all lead to habitat and biodiversity loss. ${ }^{6}$ This ultimately results in pathogen spillover from wildlife to domestic animals and 
humans while altering the abundance and distribution of certain disease vectors.

A reigning narrative exists that the consumption of exotic animals represents the sole threat for pandemics to emerge. In reality, the excess consumption of chicken, beef, and pork equally contributes to this problem. To maximize profit from meat production, animals are tightly packed together and specific genes that code for desirable traits (eg, large chicken breasts) are selected. This plethora of genetically identical animals constitutes the perfect environment for a disease to spread rapidly. Additionally, from close confinement to operations done without anesthesia, these animals are subjected to an immense amount of stress that renders them more vulnerable hosts. ${ }^{3}$ Furthermore, to counteract all the aforementioned unhealthy conditions, the routine use of prophylactic antimicrobials has been adopted in factory farms, a fact that greatly exacerbates the existing issue of antimicrobial resistance. ${ }^{7}$ Numerous examples of zoonoses that originated from meat farms already exist, like the outbreak of Nipah virus in Malaysia in the 1990s and the H1N1 pandemic in 2009. Now, more than ever, it has become evident that by abandoning industrialized farming and returning to a smaller model of raising livestock, we can maintain meat production and simultaneously reduce epidemic and pandemic risk and address the matter of animal welfare.

The eliciting factor of civil unrest is not only human overpopulation but also the innate human desire for dominance. Civil unrest can cultivate a breeding ground for an epidemic or a pandemic to erupt. In the case of the Ebola outbreak, social conflicts in the Democratic Republic of the Congo increased human-to-human transmission and devastated the regional healthcare system. ${ }^{8}$ Due to these civil disturbances, there was also a delay in the detection of the epidemic, which was officially declared after it had already spread to neighboring countries. Furthermore, political disorders and civil wars trigger human migration and cohabitation in conditions which are proper for infectious diseases to emerge. ${ }^{9}$ Poor hygiene and sanitation, malnutrition, and difficulties in healthcare supply in refugee camps have caused a lot of epidemic outbreaks during the last decade.

The effects of the anthropogenic alteration of ecosystems along with the continuous pursuit of profit are now indisputably linked to infectious disease emergence. Although we tend to portray ourselves as the victims of pandemics, in truth we are the facilitators. Drastic and decisive measures that address the aforementioned issues on a global level are urgently needed. The sooner we comprehend that "planetary health" and human health are entirely interconnected, the sooner we can start rebuilding the fundamental relationship between us and nature.

Acknowledgments. We thank Mr. Ognyan Iskrenov for assistance in preparing Figure 1.

Financial support. No financial support was provided relevant to this article.

Conflicts of interest. All authors report no conflicts of interest relevant to this article.

\section{References}

1. Taylor LH, Latham SM, Woolhouse ME. Risk factors for human disease emergence. Philos Trans R Soc Lond B Biol Sci 2001;356:983-989.

2. McFarlane R, Sleigh A, McMichael T. Synanthropy of wild mammals as a determinant of emerging infectious diseases in the Asian-Australasian region. Ecohealth 2012;9:24-35.

3. Jones B. Eating meat and not vaccinating: in defense of the analogy. Bioethics 2021;35:135-142.

4. Zhang T, Wu Q, Zhang Z. Probable pangolin origin of SARS-CoV-2 associated with the COVID-19 outbreak. Curr Biol 2020;30:1578.

5. Bezerra-Santos MA, Mendoza-Roldan JA, Thompson RCA, Dantas-Torres F, Otranto D. Illegal wildlife trade: a gateway to zoonotic infectious diseases. Trends Parasitol 2021;37:181-184.

6. Priyadarsini SL, Suresh M, Huisingh D. What can we learn from previous pandemics to reduce the frequency of emerging infectious diseases like COVID-19? Glob Transit 2020;2:202-220.

7. Cheng G, Ning J, Ahmed S, et al. Selection and dissemination of antimicrobial resistance in Agri-food production. Antimicrob Resist Infect Control 2019;8:158.

8. Wells CR, Pandey A, Ndeffo Mbah ML, et al. The exacerbation of Ebola outbreaks by conflict in the Democratic Republic of the Congo. Proc Nat Acad Sci 2019;116:24366-24372.

9. Spernovasilis N, Siakallis G, Tsiodras S, Poulakou G. Child refugees in Europe and infectious diseases: threat or threatened? Int J School Health 2017;4:1-3.

\title{
Tuberculosis behind bars in Latin America and Caribbean: A growing public health crisis
}

\author{
Zarmina Islam ${ }^{1}$, Pawan Kumar Thada², Zainab Syyeda Rahmat ${ }^{1}$, Samaa Akhtar ${ }^{3}$, Shkaib Ahmad ${ }^{4}$, \\ Ana Carla dos Santos Costa ${ }^{5}$, Mohammad Mehedi Hasan ${ }^{6,7}$, Shoaib Ahmad ${ }^{2}$ and Mohammad Yasir Essar ${ }^{8}$ \\ ${ }^{1}$ Dow University of Health Sciences, Karachi, Pakistan, ${ }^{2}$ Punjab Medical College, Faisalabad, Pakistan, ${ }^{3}$ University of London, London, United Kingdom, ${ }^{4}$ Dera \\ Ghazi Khan Medical College, Punjab, Pakistan, ${ }^{5}$ Faculty of Medicine, Federal University of Bahia, Salvador, Bahia, Brazil, ${ }^{6}$ Department of Biochemistry and \\ Molecular Biology, Faculty of Life Science, Mawlana Bhashani Science and Technology University, Tangail, Bangladesh, ${ }^{7}$ Division of Infectious Diseases, \\ The Red-Green Research Centre, BICCB, Dhaka, Bangladesh and ${ }^{8}$ Kabul University of Medical Sciences, Kabul, Afghanistan
}

Author for correspondence: Mohammad Yasir Essar, E-mail: yasir.essar@gmail.com Cite this article: Islam Z, et al. (2022). Tuberculosis behind bars in Latin America and Caribbean: A growing public health crisis. Infection Control \& Hospital Epidemiology, 43: 2000-2002, https://doi.org/10.1017/ice.2021.424
To the Editor-Despite advances in recent years to end the tuberculosis (TB) epidemic and global efforts to reduce its prevalence, the disease remains a burden on public health in several countries. In Latin America and the Caribbean, the situation is no different. With incidence rates of 61.2 per 100,000 population in the Caribbean, 46.2 in South America, and 25.9 in Mexico and 